\title{
An international comparison of childhood injuries in Hong Kong
}

\author{
Charles C Chan, J C Y Cheng, T W Wong, C B Chow, Ben P K Luis, W L Cheung, \\ Kevin Chan
}

\begin{abstract}
Objectives-This study describes 7813 childhood injuries in Shatin, Hong Kong. Supplementary analyses include developmental specificity of external causes and comparison with international childhood injury data.
\end{abstract}

Methods-Children aged 0-15 attending the accident and emergency (A\&E) department of the Prince of Wales Hospital in Hong Kong were recruited for the study. Attendance records of participants from the $A \& E$ department were analyzed. Details concerning the injury, including the International Classification of Diseases, ninth revision, external cause of injury ( $E$ code), nature of injury ( $N$ code), abbreviated injury scale, and injury severity scale constitute core measurements, along with participants' age, gender, and respective $A \& E$ procedural data.

Results-Males $(65.7 \%)$ and fall related injuries $(44.2 \%)$ predominate, while contusion $(34.6 \%)$ is the prevailing nature of injury. Two age external cause dimensions are derived from a correspondence analy-

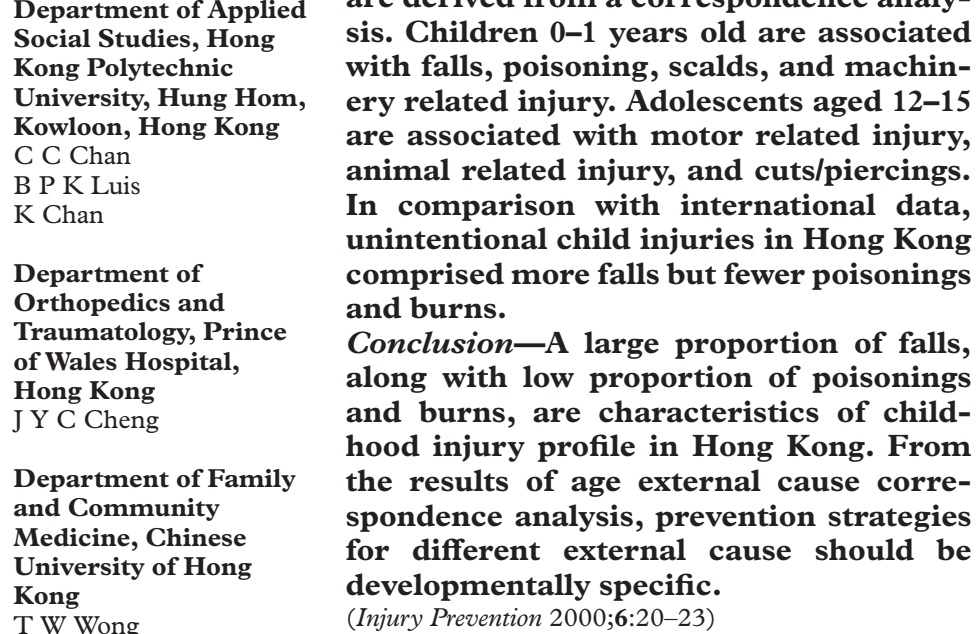

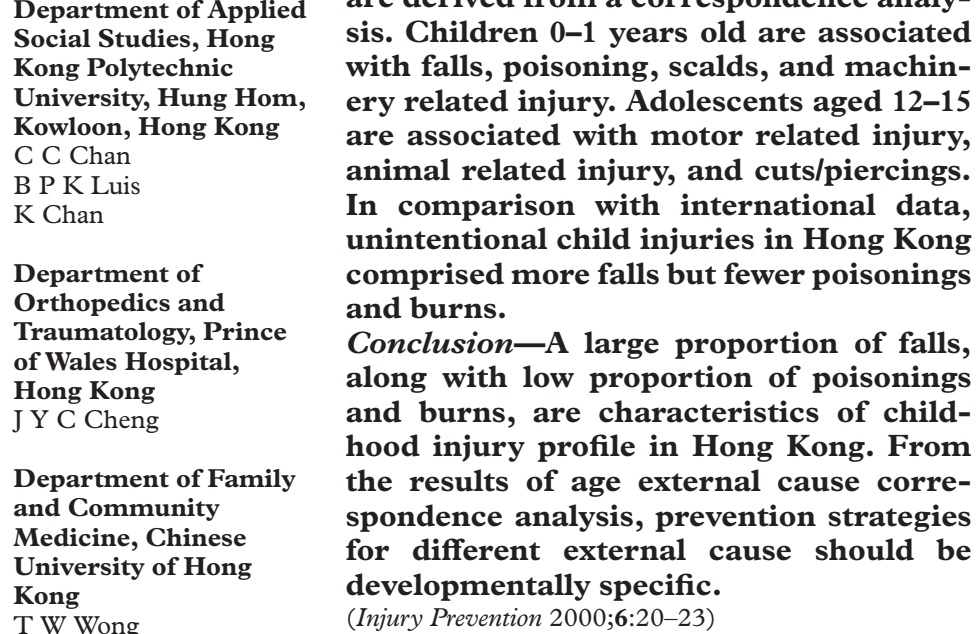

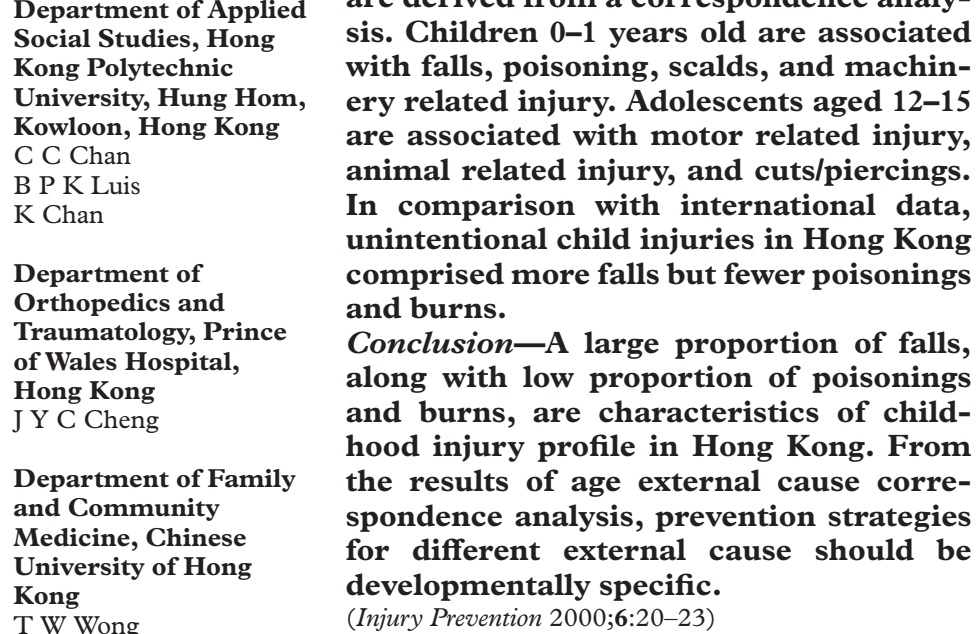

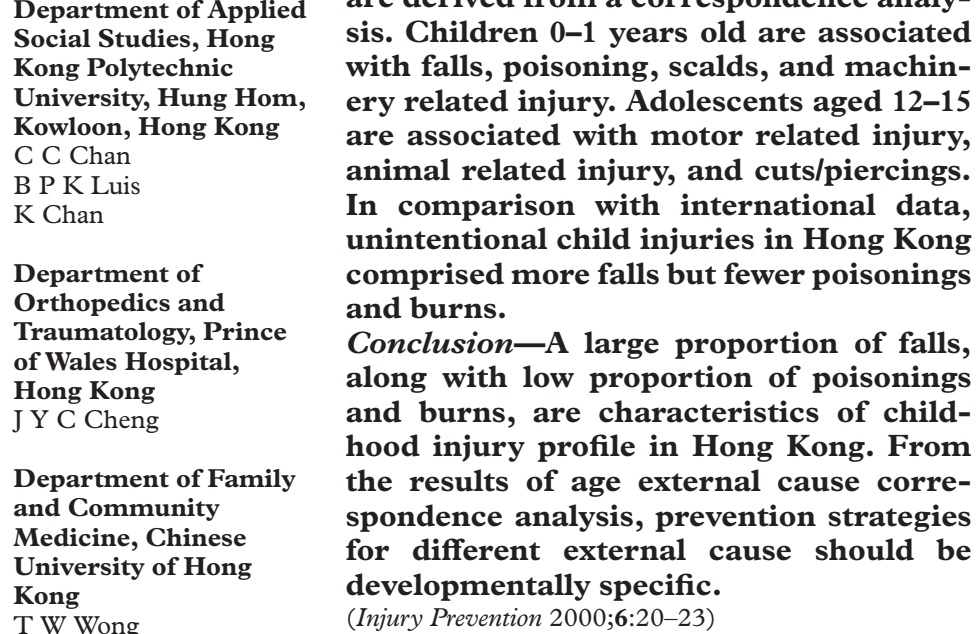

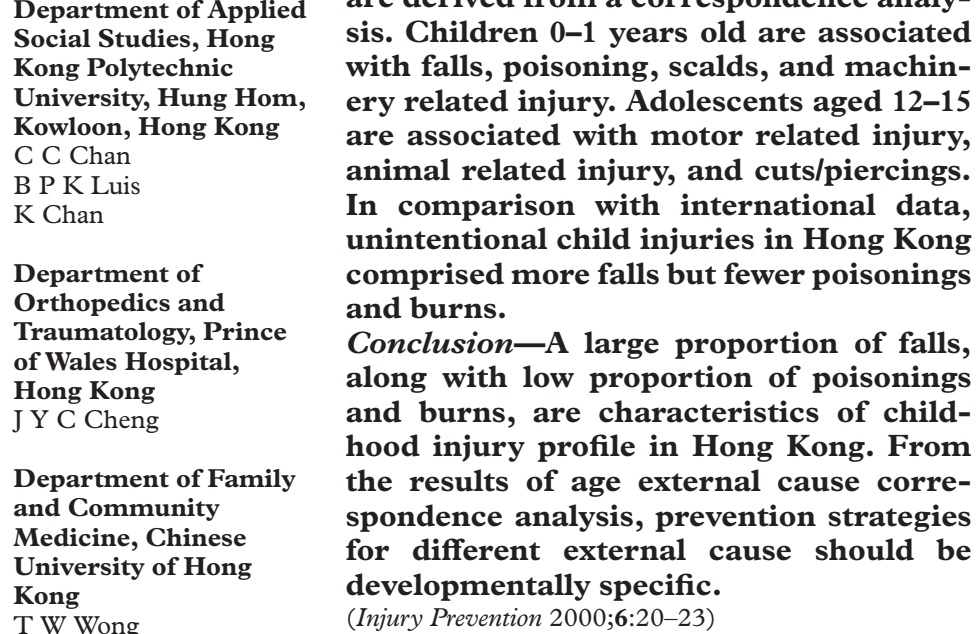

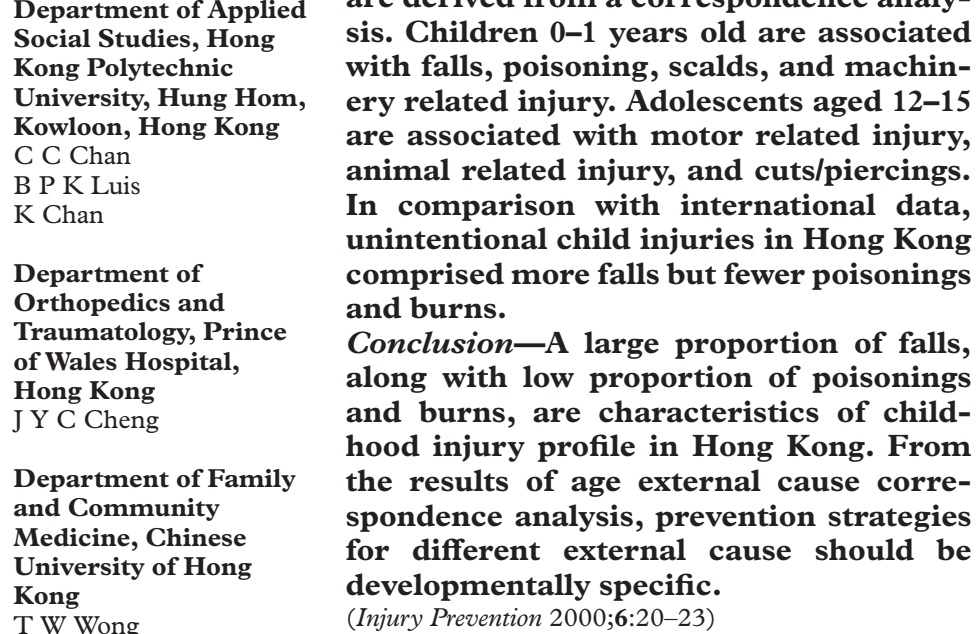

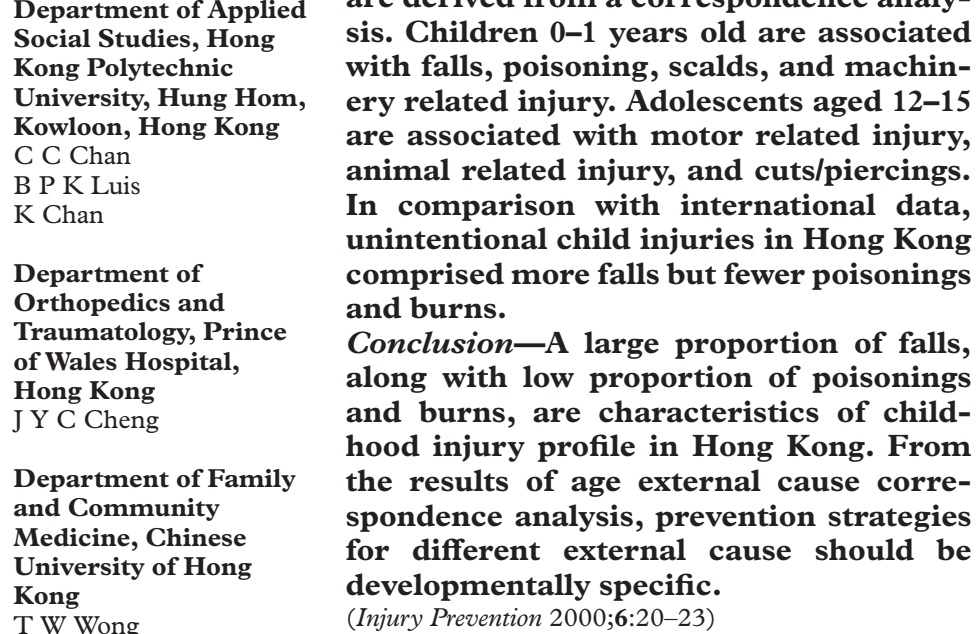

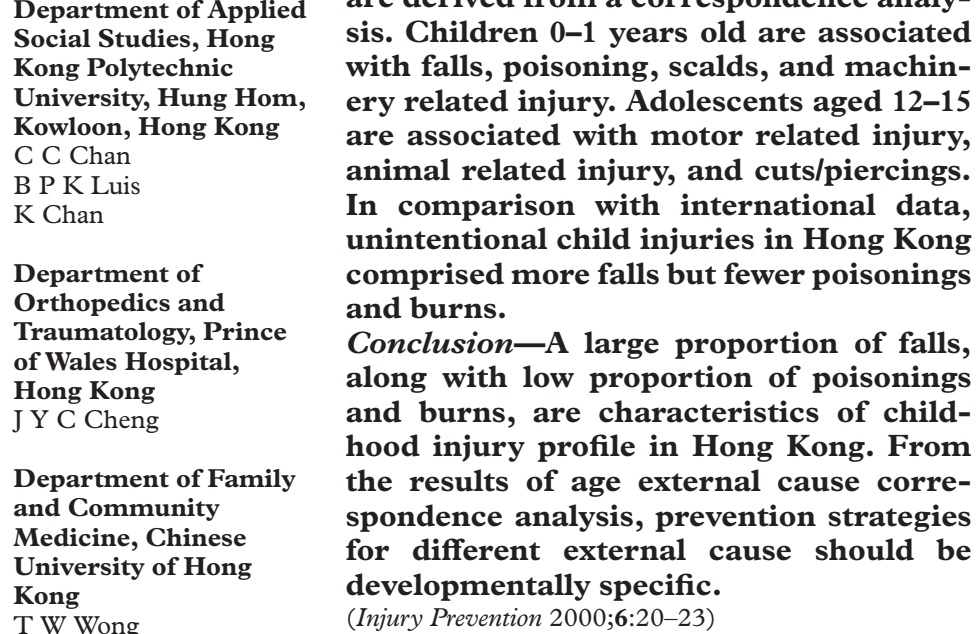

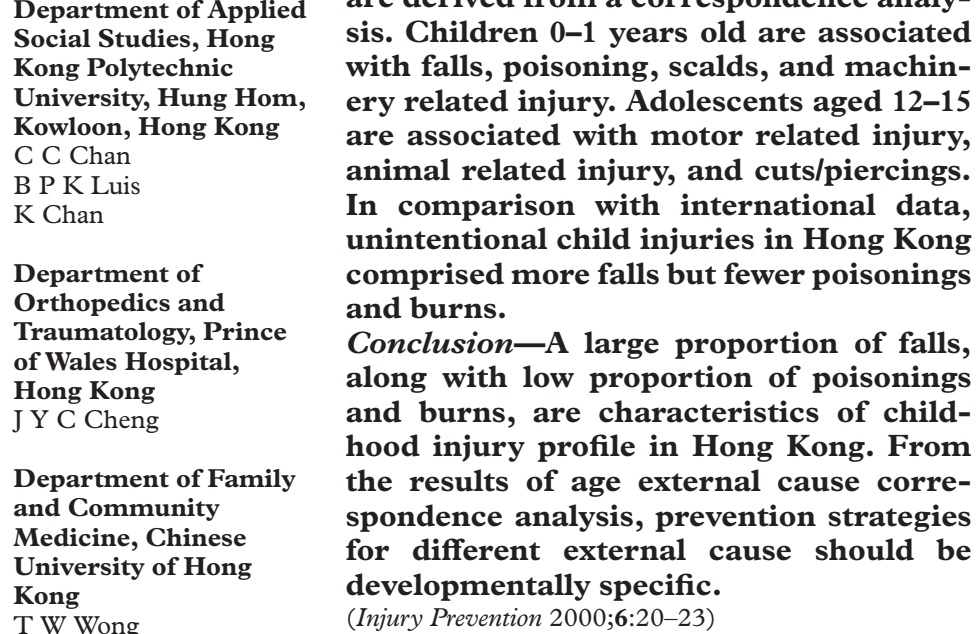

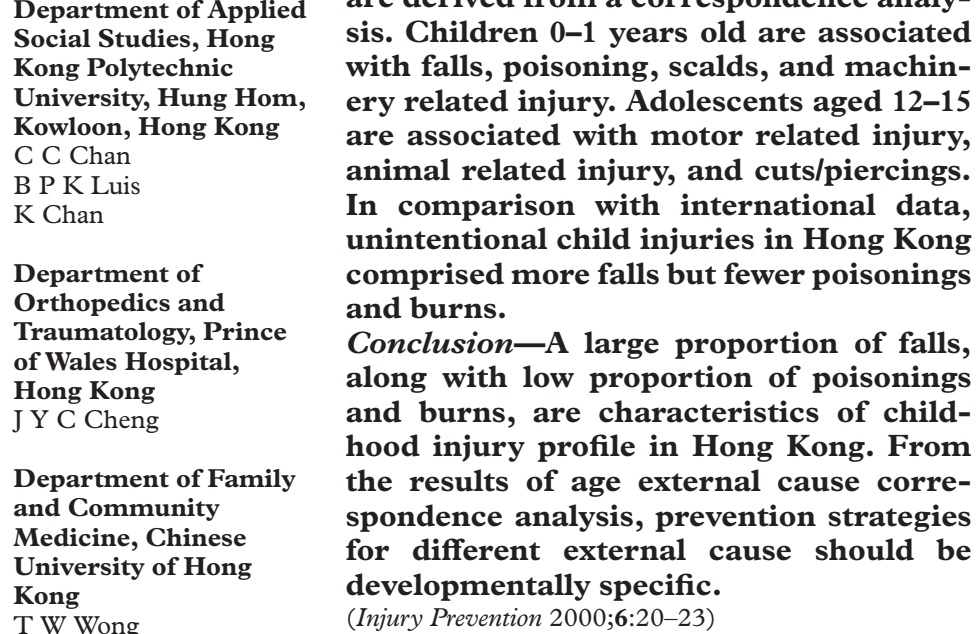

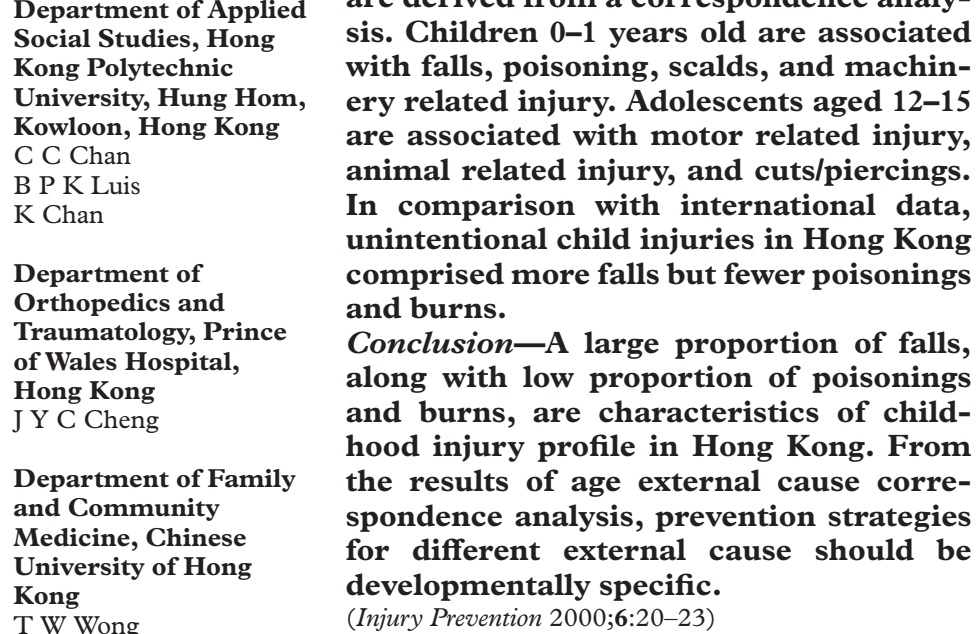

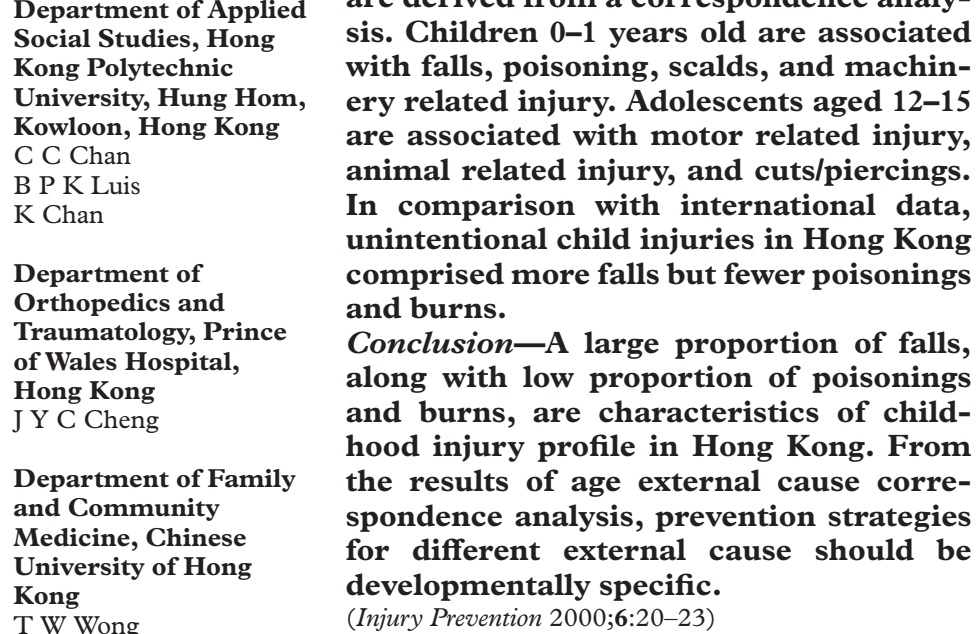

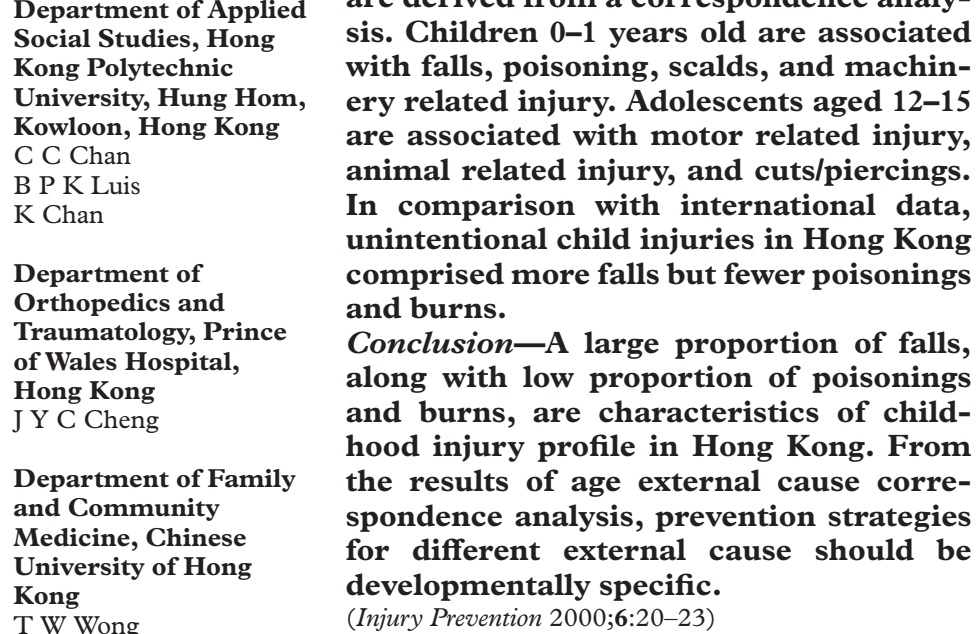

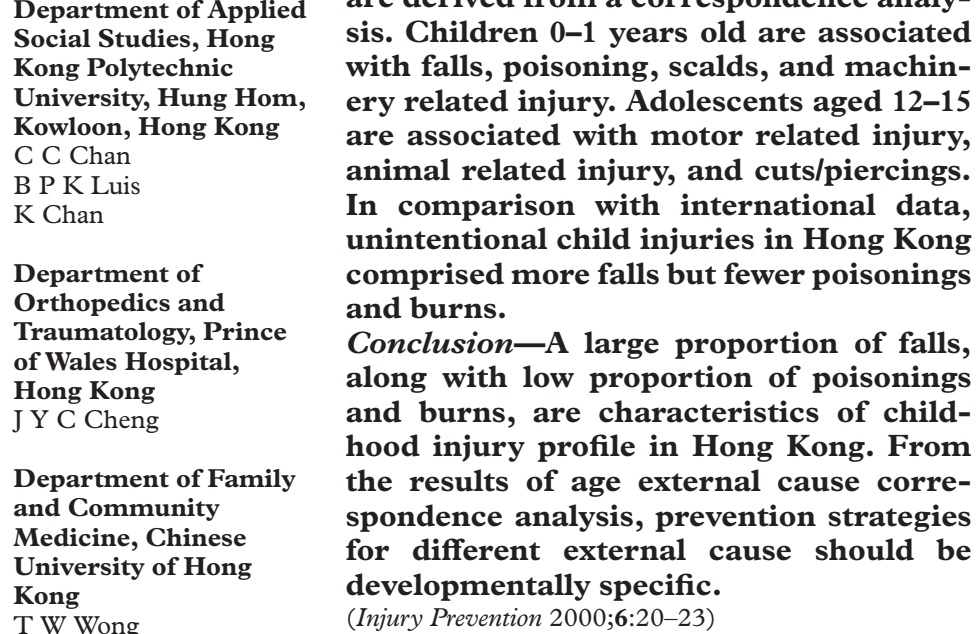

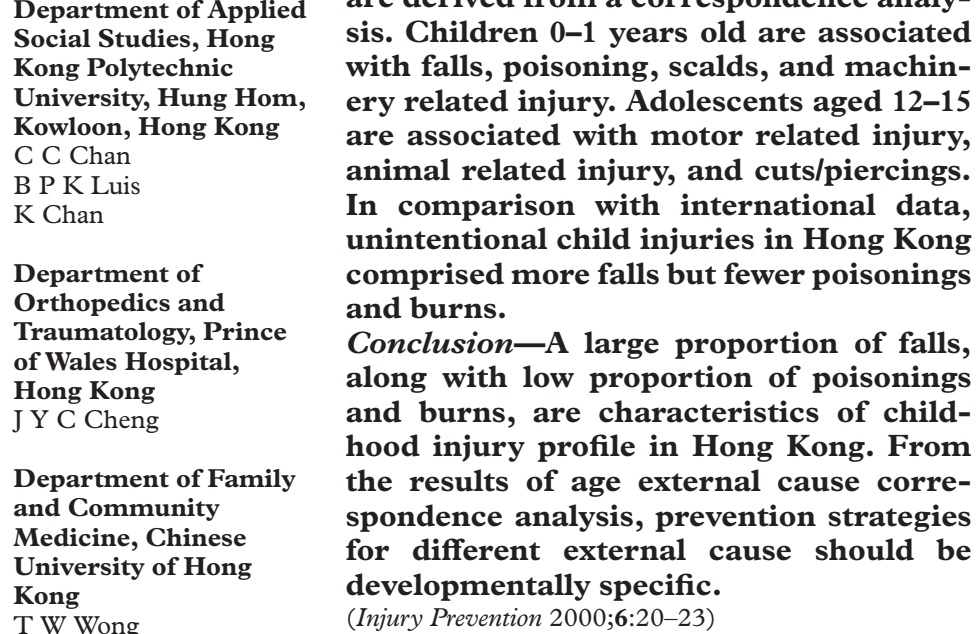

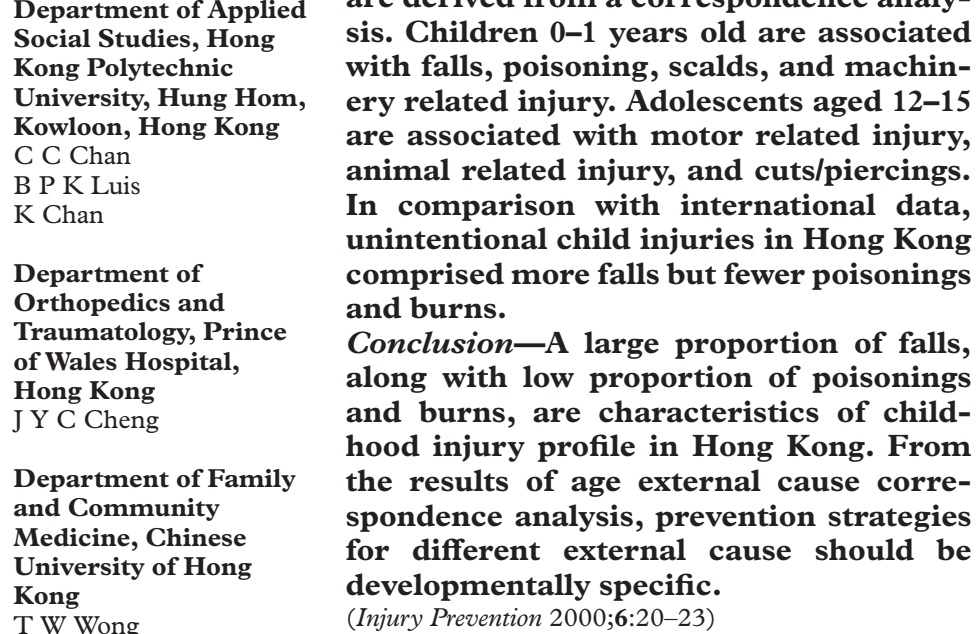

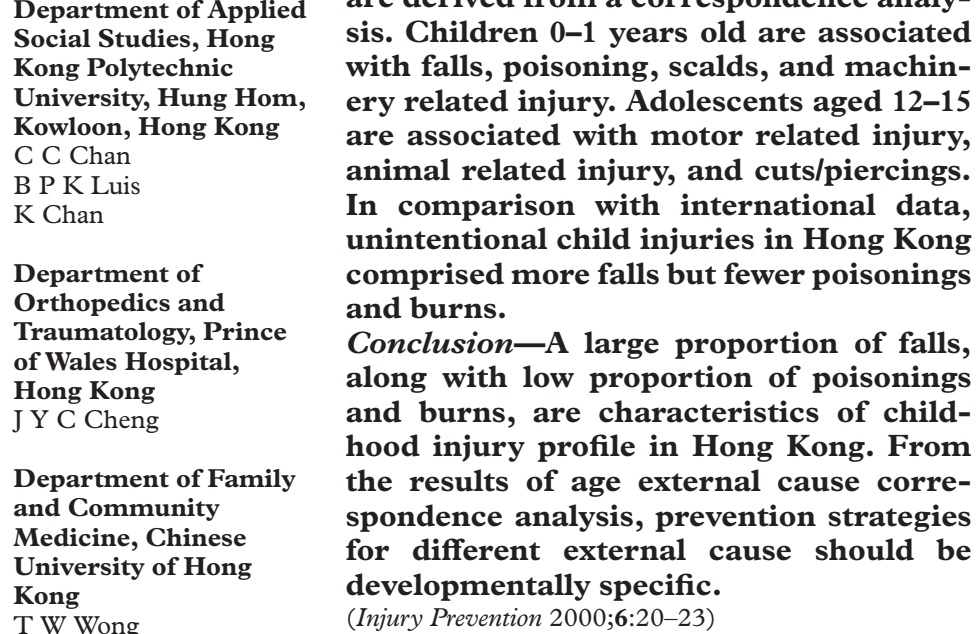

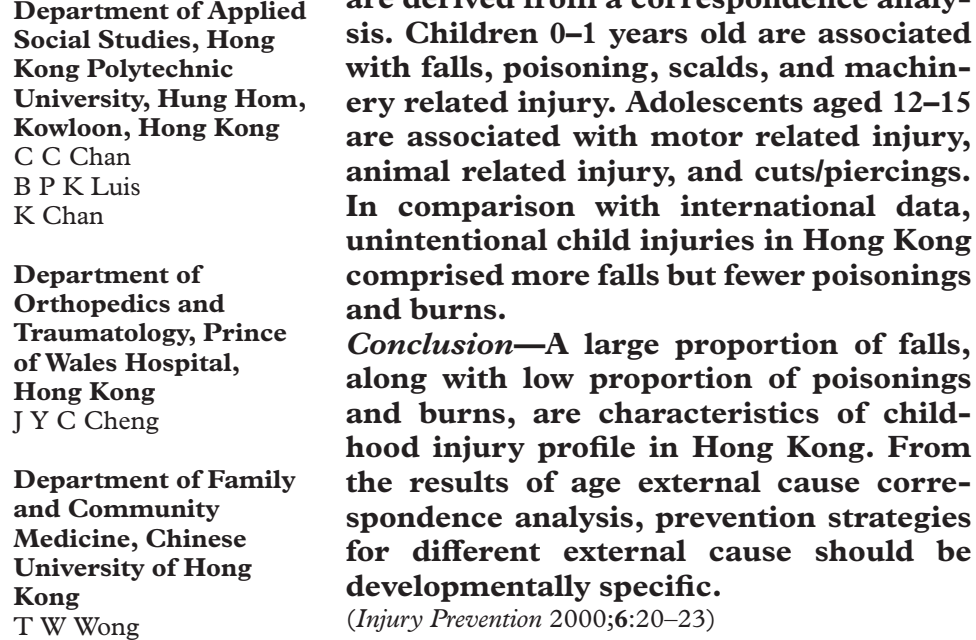

Keywords: comparative study; hospital based data; surveillance

Pediatrics, Princess

Margaret Hospital,

Hong Kong

C B Chow

Department of

Accident and

Emergency, Prince of

Wales Hospital, Hong

Kong

W L Cheung

Correspondence and reprint requests to: Dr Chan (e-mail sschchan@polyu.edu.hk)
Margaret Hospital. ${ }^{2}$ The present study was intended to: (a) replicate the previous attempt
Injury was the leading cause of death in children age 1-14 in Hong Kong between 1996 and 1997. Unintentional injuries accounted for approximately $76 \%$ of all injuries in 1996 .

There has been little interest in developing a general profile of childhood injuries in Hong Kong. The only previous attempt to do so was the study by Chow et al based in the Princess in documenting child injury morbidity and (b) compare local data with international data. Results from the present study are compared with four other sources of injury morbidity data from the United States, ${ }^{3}$ Nigeria, ${ }^{4}$ Canada, ${ }^{5}$ and Greece. ${ }^{6}$ Such a comparative analysis should permit the identification of local risk factors and contextual determinants unique to Hong Kong.

\section{Method}

Children younger than 16 attending the accident and emergency (A\&E) department of the Prince of Wales Hospital in Shatin, Hong Kong for injuries or poisoning, were included. Of all attendance records observed, 7813 fulfilled these selection criteria.

\section{PROCEDURES}

Attendance records from the A\&E department of the Prince of Wales Hospital were collected between 1996 and 1997. This hospital ranked third among hospitals in Hong Kong in terms of $\mathrm{A} \& \mathrm{E}$ admissions (Hospital Authority, 1996) and is one of the two teaching hospitals in Hong Kong. The following fields on the attendance records were analyzed: age, gender, admission time and date, triage (that is, priority for treatment), medical imaging, specialty, discharge destination, level of consciousness on arrival, and nature of injury. In addition, the International Classification of Diseases, ninth revision (ICD-9), external causes of injury (E code), nature of injury ( $\mathrm{N}$ code), ${ }^{7}$ abbreviated injury scale (AIS), and the injury severity scale (ISS) ${ }^{8}$ were derived from comments on the records.

Table 1 Nature of injury ( $N$ code): Prince of Wales Hospital 1996-97, * ages 0-14 years

\begin{tabular}{ll}
\hline$N$ code & $\begin{array}{l}\text { Frequency } \\
(\%)\end{array}$ \\
\hline Fracture of skull/neck/trunk (N800-N809) & $78(1.1)$ \\
Fracture of upper limb (N810-N819) & $862(11.7)$ \\
Fracture of lower limb (N820-N829) & $141(1.9)$ \\
Dislocation (N830-N839) & $100(1.4)$ \\
Sprains (N840-N848) & $462(6.2)$ \\
Intercranial (N850-N854) & $44(0.6)$ \\
Open wound of skull/neck/trunk (N870-N879) & $1158(15.7)$ \\
Open wound of upper limb (N880-N887) & $311(4.2)$ \\
Open wound of lower limb (N890-N897) & $214(2.9)$ \\
Blood (N900-N904) & 2 \\
Superficial (N910-N919) & $927(12.5)$ \\
Contusion (N920-N924) & $2555(34.6)$ \\
Crushing (N925-N929) & $97(1.3)$ \\
Foreign objects entering through orifice & $176(2.4)$ \\
$\quad$ N930-N939) & \\
Burn and scald (N940-N949) & $231(3.1)$ \\
Central nervous system (N950-N957) & 1 \\
Others (N958-N959) & $36(0.4)$ \\
Total & $7395(100)$
\end{tabular}

$\star \mathrm{N}$ code was not available in 418 cases. 
Table 2 Mechanism of injury (E code): Prince of Wales Hospital 1996-97, ${ }^{\star}$ ages $0-14$ years

\begin{tabular}{ll}
\hline E code & $\begin{array}{l}\text { Frequency } \\
(\%)\end{array}$ \\
\hline Motor (E800-E829) & $861(12.0)$ \\
Watercraft (E830-E838) & $5(0.1)$ \\
Aircraft (E840-E845) & $20(0.3)$ \\
Poisoning (E850-E869) & $35(0.5)$ \\
Surgical/medical care (E870-E876) & 3 \\
Falls (E880-E888) & $3174(44.2)$ \\
Burns (E890-E899) & $6(0.1)$ \\
Extreme environment (E900-E904) & 1 \\
Animal (E905-E906) & $156(2.2)$ \\
Natural disaster (E907-E909) & 1 \\
Drowning/submersion (E910) & $7(0.1)$ \\
Suffocation (E911-E913) & $17(0.2)$ \\
Intrusion into orifice (E914-E915) & $174(2.4)$ \\
Struck by others (E917) & $1304(18.2)$ \\
Caught between objects (E918) & $215(3.0)$ \\
Machinery (E919) & $11(0.2)$ \\
Cut/piercing (E920) & $321(4.5)$ \\
Explosion (E921, E923) & $14(0.2)$ \\
Scald (E924) & $213(3.0)$ \\
Electric shock/radiation (E925) & 3 \\
Sports (E927) & $294(4.1)$ \\
Other environmental (E928) & 1 \\
Medication in therapeutic course (E930-E949) & $8(0.1)$ \\
Self inflicted (E950-E959) & $10(0.1)$ \\
Assault (E960-E969) & $314(4.4)$ \\
Legal intervention (E970-E978) & 3 \\
Unknown intent (E980-E989) & 2 \\
Total & $7173(100)$ \\
\hline × code was not avalable in 418cases &
\end{tabular}

${ }^{\star}$ E code was not available in 418 cases.

To test for any patterns of external causes across the span of development, a correspondence analysis was performed on 32 major groups of external causes and their relationship with six age groups: infants and 1, 2-4, 5-7, $8-11$, and $12-15$ years. An inclusion criteria was set with row points (various external causes) correlation $>0.2$ and a minimum of 10 occurrences in an external cause category.

DATA QUALITY

Incomplete cases comprised $11.3 \%$ of all 7813 records studied. They could be attributed to poor scanning quality of attendance records or insufficient annotations for coding. In particu-

Table 3 Percentage occurrence of injuries by E code: Hong Kong, USA, Nigeria, Canada, and Greece, $0-14$ year olds *

\begin{tabular}{llllll}
\hline E code & Hong Kong & USA & Nigeriat & Canada & Greece \\
\hline Falls & 44.3 & 27.7 & 25.0 & 35.6 & 44.3 \\
Transport injuries & 12 & 5.7 & 26.5 & 8.1 & 3.6 \\
Poisonings & 0.5 & 2.4 & 3.8 & 1.8 & 2.1 \\
Burns & 0.1 & 1.7 & 7.3 & 1.9 & 2.0 \\
Struck by others & 18.2 & 13.7 & N/A & N/A & 21.8 \\
Cut/piercing & 4.5 & 7.3 & 3.5 & N/A & 3.3 \\
Other external causes & 20.4 & 41.5 & 33.9 & 52.6 & 22.9 \\
M:F ratio & $1.9: 1$ & $1.3: 1$ & $1.5: 1$ & $1.4: 1$ & $1.7: 1$ \\
$\begin{array}{l}\text { Additional data from } \\
\text { Urban rural, 1995 }\end{array}$ & statistics & & & & \\
$\quad$ Urban & 95 & 76 & 40 & 77 & 59 \\
$\quad$ Rural & 5 & 24 & 60 & 23 & 41 \\
$\quad$ Under 15, 1999 & 18 & 22 & 43 & 19 & 15 \\
$\quad$ Under 15 years & & & & & \\
\hline
\end{tabular}

\section{$\star$ Source}

Burt C, Fingerhut L. Injury visits to hospital emergency departments: United States, 1992-95. Vital Health Statistics. Hyattsville, Maryland: National Center for Health Statistics, 1998;13(131). Adesunkanmi ARK, Oyelami AOO. Epidemiology of childhood injury. F Trauma 1998;44:506-11. Health Canada. For the safety of Canadian children and youth: from injury data to preventive measures. Ottawa, Canada: Minister of Public Works and Government Services, Canada, 1997.

Center for Research and Prevention of Injuries among the Young (CEREPRI). Greek injury data from Emergency Department Injury Surveillance System (EDISS). Greece: CEREPRI, 1995.

Population Division of the United Nations Secretariat. World urbanization prospects. (1996 revision.) United Nations, 1996.

Population Division of the United Nations Secretariat. Sex and age annual 1950-2050. (1998 revision.) 1997 Demographic yearbook. United Nations publication, 1998.

†Children of $0-15$, rather than $0-14$, were included. lar, the percentages of cases with missing AIS, $\mathrm{E}$ and $\mathrm{N}$ codes were $7.8 \%, 8.2 \%$, and $5.5 \%$, respectively.

Reliability of injury coding from attendance records was measured by inter-rater agreement between a research nurse and a physician on $\mathrm{E}$ code, $\mathrm{N}$ code, AIS, and ISS, from a random sample of 200 cases. Agreements on E code, N code, AIS, and ISS were $80.5 \%, 69.0 \%$, $59.5 \%$, and $93.0 \%$ respectively.

\section{Results}

GENDER AND AGE

In this study there was a male to female ratio of 1.9:1, which increased with age.

TYPE OF INJURY

Home injury accounted for the majority $(43.6 \%)$ of cases and sports injury was the second most frequent (13.8\%). Most children $(95.0 \%)$ arrived at the $\mathrm{A} \& \mathrm{E}$ service conscious, $46.6 \%$ had radiography, $15.1 \%$ were admitted, and $13.5 \%$ required operative treatment.

\section{SEVERITY}

Altogether 7205 AIS scores were assigned from annotated records. The mean (SD) maximum AIS score was $1.18(0.42) ; 83.4 \%$ scored and $15.6 \%$ had a score of 2 .

Agreement was found between triage destinations and AIS. When patients arrived at the hospital, each one was assigned to one of four service priorities according to a triage system. Altogether $85.0 \%$ were classified as semiurgent, $11.9 \%$ as urgent, $2.8 \%$ as non-urgent, and $0.3 \%$ as critical. These triage destinations correlated significantly with AIS $(r=0.266$, $\mathrm{p}<0.01$ ).

\section{NATURE OF INJURY}

An ICD $\mathrm{N}$ code is required in all Prince of Wales Hospital attendance records. Table 1 shows that contusion was the most common $\mathrm{N}$ code $(34.6 \%)$ followed by an open wound of skull, neck, or trunk (15.7\%), superficial injuries $(12.5 \%)$, and fracture of the upper limb $(11.7 \%)$. Combining $\mathrm{N}$ code and $\mathrm{E}$ code, the three most common combinations were fall and contusion $(17.8 \%)$, fall and fracture of upper limb (8.6\%), and struck by others and contusion $(7.6 \%)$.

EXTERNAL CAUSES OF INJURY

A total of 7173 cases contained sufficient information for valid $\mathrm{E}$ coding. These were categorized into 27 major $\mathrm{E}$ code categories (table 2). "Falls" was the most common external cause $(44.2 \%), 23 \%$ of which led to fracture, and $0.7 \%$ had an intracranial injury.

"Struck by others" (18.2\%) and "motor injuries" (12\%) were the next leading E codes. All other $24 \mathrm{E}$ code categories accounted for $25.6 \%$ with each recorded external cause accounting for fewer than $5 \%$ of valid cases.

\section{AGE EXTERNAL CAUSE INTERACTIONS}

Two dimensions of age external cause interactions emerged from the analysis. The first comprised infants and 1 year olds along with 
poisoning, falls, machinery related injuries, and scalds. The age group 12-15 loaded onto a second dimension with external causes that included motor related, animal related, and cuts/piercings.

INTERNATIONAL COMPARISONS

To shed further light on these findings, data from four hospital based studies in USA, ${ }^{3}$ Nigeria, ${ }^{4}$ Canada, ${ }^{5}$ and Greece $^{6}$ were examined. As the assembled data used different age categorizations, results are compiled for all age groups combined.

\section{Discussion}

The main age external cause dimensions revealed in this study showed that for those under 2 poisonings, falls, and scalds dominate. Chan and Critchley offer three explanations for the poisonings: packaging, storage, and accessibility. ${ }^{9}$ Transparent packaging made colorful drugs visible to younger children, thus attracting their attention. Many homes store insecticides on the floor, increasing their accessibility. The availability of domestic medicines (cough syrup, flu/cold capsules, painkillers) without prescription at local pharmacies may also increase accessibility to poisoning agents.

The preponderance of scalds in this age group is consistent with findings reported from the United States ${ }^{10}$ and may reflect increasing mobility during this stage of development. ${ }^{11}$

The dominant pattern for older children, ages 12-15, involves more speculation. Among those who suffered from a motor related injury, $69.4 \%$ involved pedal cycles. The Transport Department of Hong Kong revealed that in $1995,18 \%$ of all pedal cycle related casualties involved adolescents aged $10-14 .^{1}$ The absence of any bicycle helmet regulations may be one factor behind this phenomenon. The high proportion of pedal cycle injuries may, however, be confounded by the geographical district studied. The Shatin district has one of the busiest cycling paths in Hong Kong.

As shown in table 3, in comparison with the other countries, it appears that poisoning and burns were less frequent causes of injuries in Hong Kong, whereas falls were more frequent. A possible explanation, particularly for burns, is the popularity of traditional Chinese medicine. Many mothers in Hong Kong prefer applying oil or medical creams that are sold over the counter, which could have grave consequence if the burn was severe.

The preponderance of boys in injuries appears to be an international phenomenon and has been widely reported. ${ }^{12-14}$ Gender socialization may result in different beliefs and attributions that lead to different risk taking behaviors. ${ }^{15-17}$ The higher male to female ratio in the Hong Kong data suggests local children could be subjected to gender socialization regarding injury beliefs and risk taking behaviors more intensively than elsewhere.

Falls are the most common external cause in all countries compared, except Nigeria. They are particularly predominant in Hong Kong and Greece, both at $44.3 \%$ among all injuries studied. Much of this could be attributed to the geography of Hong Kong. Whereas some other countries feature a mix of high density cities and suburban settlements, and data from the Nigerian study were mostly from rural areas. Hong Kong, by contrast, is $95 \%$ urbanized $^{18}$ with many residing in crowded high rise homes. We speculate that such homes partly explain why falls are so common in Hong Kong.

However, if population density and urbanization are associated with relative predominance of falls, Greece presents an exception. According to United Nations statistics in 1996, $41 \%$ of the Greek population resided in rural areas, ${ }^{18}$ but the Greek data were collected from urban and rural hospitals. ${ }^{6}$ Striking injuries were the second most frequent external cause in all the countries compared. This could indicate that many of the injuries of people admitted to hospital lie in the grey zone between unintentional and intentional. ${ }^{19}$

\section{LIMITATIONS}

$\mathrm{A} \& \mathrm{E}$ attendance records were chosen as the source of data in this study for pragmatic reasons. Although basic routine data are less than ideal when details surrounding injuries are needed, they are often a valuable source of injury information because they are accessible and do not entail excessive resources.

The low AIS and ISS scores among participants is not surprising and the measures were designed primarily for mortality purposes. Accordingly, they are not sensitive enough for assessing morbidity in mild to moderate injuries. Other severity measures are needed in such situations.

Inter-rater reliability of injury coding, including E code, $\mathrm{N}$ code, AIS, and ISS, was satisfactory but could be further improved if $\mathrm{E}$ code and AIS were made mandatory for all local hospital attendance records.

Only selected items were analyzed in the international comparisons because of incompatible definitions. One remedy is to obtain a consensus among researchers in this field on the categorization of injury data, including external causes, age grouping, and other demographic data. ${ }^{20}$ The World Health Organization multicentre study on childhood accidents in the Western Pacific Region, ${ }^{21}$ and the Common Data Elements Implementation Guide from the Centers for Disease Control in $\mathrm{USA}^{22}$ are examples of efforts to unify injury data.

\section{Implications for prevention}

The patterns of childhood injuries in Hong Kong indicate that falls deserve more in-depth study whereas poisoning and burns might be overstated as common causes of pediatric trauma in this city.

The age external cause dimensions could provide strategic insights in formulating developmentally specific prevention interventions. To prevent falls, scalds, poisonings, and machinery related injuries among infants and toddlers, passive interventions are preferable, 
such as rearranging furniture or using physical restraints like seat belts and window guards. For injuries involving older children and adolescents, active interventions could be more effective if rules could be generalized to various types of hazards.

Because unintentional child injuries in Hong Kong are characterized by an injury profile localized among a few external causes, local health professionals involved in injury prevention in Hong Kong should find it simpler to identify their promotional targets.

The authors belong to the Childhood Injury Prevention Research Group, Hong Kong. We wish to acknowledge the generous financial support from the Child Orthopedic Research Foundation, Society for the Relief of Disabled Children, and the Network for Health and Welfare Studies, Department of Network for Health and Welfare Studies, Department of
Applied Social Studies, Hong Kong Polytechnic University. We Applied Social Studies, Hong Kong Polytechnic University. We are also grateful for permission to use clinical data from the Hospital Authority, Hong Kong and the A\&E Department and
Surgery Department of Prince of Wales Hospital and for general Surgery Department of Prince of Wales Hospital and for general
support from the Departments of Traumatology and Orthopedsupport from the Departments of Traumatology and OrthopedHong Kong.

1 Department of Health. Public health report. Hong Kong: Department of Health, Hong Kong, 1998: 41-62.

2 Chow CB, Chan KH, Chiu LH. Childhood injuries in Hong Kong: a one-year surveillance program at an accident and emergency department. Hong Kong fournal of Paediatrics 1993; special issue: $196-212$

3 Burt C, Fingerhut L. Injury visits to hospital emergency departments: United States, 1992-95. Vital health statistics. Hyattsville, Maryland: National Center for Health Statistics, 1998.

4 Adesunkanmi ARK, Oyelami AOO. Epidemiology of childhood injury. F Trauma 1998;44:506-11.

5 Health Canada. For the safety of Canadian children and youth: from injury data to preventive measures. Ottawa, Canada: from injury data to preventive measures. Ottawa, Canada:
Minister of Public Works and Government Services, Canister of 1997.

6 Center for Research and Prevention of Injuries among the Young. Greek injury data from Emergency Department Injury
Surveillance System (EDISS). Greece: CEREPRI, 1995.
7 World Health Organization. International classification of diseases, ninth revision (ICD-9). Geneva, Switzerland: WHO, eases, 1978 .

8 Association for the Advancement of Automobile Medicine. The abbreviated injury scale, 1990 revision. Des Plaines, USA: AAAM, 1990.

9 Chan TYK, Critchley JAJ. Childhood poisoning in Hong Kong. Hong Kong Medical fournal 1996;2:191-5.

10 McLoughlin E, McGuire A. The causes, cost, and prevention of childhood burn injuries. Am 7 Dis Child 1990;144:677-83.

11 Peterson L, Saldana L. Accelerating children's risk for injury: mothers' decisions regarding common safety rules. $\mathcal{F}$ Behav Med 1996;19:317-31.

12 Bangdiwala SI, Anzola-Pérez E. The incidence of injuries in young people. 2. Log-linear multivariable models for risk-factors in a collaborative study in Brazil, Chile, Cuba and Venezuela. Int $\mathcal{F}$ Epidemiol 1990;19:125-32.

13 Bener A, El-Rufaie OEF, Al-Suweidi NEK. Pediatric injuries in an Arabian Gulf country. Inj Prev 1997;3:224-6.

14 Laflamme L, Eilertpetersson E. Injuries to preschool children in a home setting: patterns and related products. Acta Paediatr 1998;87:206-11.

15 Morrongiello BA, Rennie H. Why do boys engage in more risk taking than girls: the role of attributions, beliefs, and risk appraisals. F Pediatr Psychol 1998;23:33-43.

16 Hillier LM, Morrongiello BA. Age and gender differences in school-age children's appraisals of injury risk. 7 Pediatr Psyschool-age children's app

17 Morrongiello BA, Dawber T. Toddlers' and mothers' behaviors in an injury-risk situation: implications for sex differences in childhood injuries. F Appl Dev Psychol 1998; 19:625-39.

18 Population Division of the United Nations Secretariat. World urbanization prospects: the 1996 revision. New York: United Nations, 1996.

19 Peterson L. Integrating child injury and abuse-neglect research: common histories, etiologies, and solutions. Psychol Bull 1994;116:293-315.

20 Christoffel KK, Scheidt PC, Agran PF, et al. Standard definitions for childhood injury research: excerpts of a conference report. Pediatrics 1992;89:1027-34

21 The current state of knowledge and research in child injuries in Hong Kong: some thoughts on the research agenda. WHO multicentre study on childhood accidents in the Western Pacific region. 27-30 July 1994, Beijing, China.

22 Centers For Disease Control. Common data elements implementation guide (version 1.6). US Department of Health and Human Services, 1998 (url: http:// www.cdc.gov/data/index.htm).

\section{Income from speed cameras}

Traffic speed cameras are the fastest growing source of revenue for the NSW government with revenues up $80 \%$ in the past year. Revenue rose from $\$ 3.5 \mathrm{~m}$ (Aus) in $1993-4$ to $\$ 14.3 \mathrm{~m}$ in $1997-98$ and $\$ 25.4 \mathrm{~m}$ in $1998-99$. The number of tickets issued to motorists have almost doubled in the past year from 139000 to 271600 . Speed camera revenue is an increasing part of fine revenue totalling $\$ 120 \mathrm{~m}$ because revenues from red light cameras, parking, and traffic fines have fallen. Increasingly sophisticated mobile radar units have improved the ability of police to catch speeding drivers. The numbers are likely to rise as new technology permits digital cameras in permanent locations for the first time (Sydney Morning Herald, December 1999).

Funding and disease burden

A report appearing in the New England fournal of Medicine (1999;340:1881-7) clearly demonstrated what many of us long thought: that the amount of research funding, in this case National Institutes of Health funding in the US, is only partly related to the burden of disease when disease burden is measured as incidence, prevalence or number of hospital days involved, and only weakly associated with deaths and years of life lost; disability adjusted life years were strongly predictive of funding. Interestingly, however, even with this measure injuries are barely mentioned. Not surprising as few think of injuries as a disease.

\section{Just a reminder}

Not only do $20 \mathrm{mph}$ zones work, especially if there is a scintilla of enforcement, but so do speed cameras. A report in the British Medical fournal (1998;316:5-6) described a six year experiment with speed cameras on west London trunk roads in which there was a threefold reduction in number of deaths and a fall in the number of serious and minor injuries of about one quarter. American studies suggest that an $8 \%$ reduction of fatal accidents results is associated with each reduction in average speed of one mile per hour. Still to be answered is whether these results are sustainable and repeatable elsewhere, and are they exportable. 